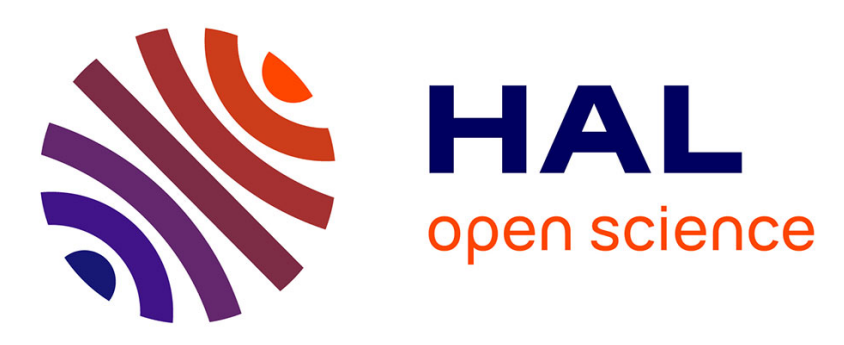

\title{
Pilot evaluation of the Frankfurt Social Skills Training for children and adolescents with autism spectrum disorder
}

Evelyn Herbrecht, Fritz Poustka, Sabine Birnkammer, Eftichia Duketis, Sabine Schlitt, Gabriele Schmötzer, Sven Bölte

\section{To cite this version:}

Evelyn Herbrecht, Fritz Poustka, Sabine Birnkammer, Eftichia Duketis, Sabine Schlitt, et al.. Pilot evaluation of the Frankfurt Social Skills Training for children and adolescents with autism spectrum disorder. European Child and Adolescent Psychiatry, 2009, 18 (6), pp.327-335. 10.1007/s00787-0080734-4 . hal-00478082

\section{HAL Id: hal-00478082 \\ https://hal.science/hal-00478082}

Submitted on 30 Apr 2010

HAL is a multi-disciplinary open access archive for the deposit and dissemination of scientific research documents, whether they are published or not. The documents may come from teaching and research institutions in France or abroad, or from public or private research centers.
L'archive ouverte pluridisciplinaire HAL, est destinée au dépôt et à la diffusion de documents scientifiques de niveau recherche, publiés ou non, émanant des établissements d'enseignement et de recherche français ou étrangers, des laboratoires publics ou privés. 
Evelyn Herbrecht

Fritz Poustka

Sabine Birnkammer

Eftichia Duketis

Sabine Schlitt

Gabriele Schmötzer

Sven Bölte

\section{Pilot evaluation of the Frankfurt Social Skills Training for children and adolescents with autism spectrum disorder}

Received: 12 December 2007

Accepted: 1 October 2008

Published online: 22 January 2009

E. Herbrecht, MD ( $\square)$

Department of child and Adolescent

Psychiatry and Psychotherapy

J. W. Goethe University

Deutschordenstrasse 50

60528 Frankfurt IM, Germany

E-Mail: herbrecht@em.uni-frankfurt.de

F. Poustka, MD - E. Duketis, MD

S. Schlitt · G. Schmötzer, MD

S. Bölte, $\mathrm{PhD}$

J. W. Goethe University

Frankfurt IM, Germany

S. Birnkammer

Ludwig-Maximilians University

Frankfurt IM, Germany
Abstract The objective of this pilot study was to evaluate the effectiveness of a group-based intervention aiming at improving social and communication skills in individuals with autism spectrum disorder. Over a period of 11 months, $N=17$ children and adolescents received treatment according to the manualised Frankfurt Social Skills Training (KONTAKT). Parent, teacher, expert and blind expert ratings were assessed to judge outcome regarding peer interaction, autistic behaviours, adaptive functioning and family burden. The participants exhibited improvements pre to follow-up treatment, particularly in the area of autistic symp- tomatology. Effect sizes (partial eta squared) ranged from 0.02 to 0.69 . Among other things, regression models showed a positive influence of IQ and language skills on gains in social skills. Findings indicate that KONTAKT might be useful for enhancing social skills and reducing autism-related psychopathology over time in different contexts. Nevertheless, controlled trials are needed to reassure its effectiveness.

Key words group intervention - effectiveness communication - social interaction - autism

\section{Introduction}

Impairments in social interaction are viewed the core deficit underlying all autism spectrum disorders. An increasing number of group-based programmes has been presented to improve social skills. These can be roughly classified by type of mediation (e.g. adult experts, typical peers) and setting (e.g. clinical, within-school) [26]. The first descriptions of group social skills approaches designed for individuals with autism date from some 20 years ago [21, 35]. They focussed on improvement of communication and interaction skills and on the facilitation of positive social experiences with peers. Even today, these elements are integral parts of almost all pub- lished group-based social skills training programmes. Still, programmes differ considerably in terms of overall duration, frequency and duration of session, group composition, trainer ratio, strategic and operative teaching methods. As to the matters of teaching methods, several principles have been proposed as promising across different studies, such as the conveyance of social engagement as fun, an encouraging and nurturing learning atmosphere, the teaching of social skills and progressive learning in concrete terms, a high degree of training predictability and structure and multiple learning and practice opportunities $[2,18,36]$.

Despite a widespread use in clinical practice, until more recently, little hard evidence on the effectiveness of social skills training programmes was published. 
Currently, it seems likely that group-based social skills interventions are efficient, see [36] for a comprehensive review. However, evaluation studies highly differ in terms of sample characterisation, standardization of training procedures and type of outcome measures. Some studies obtained qualitative data from parents and trainers [20,21], whereas others used standardized instruments and pre-post-design $[2,23,34,35]$. Whereas study results concordantly indicate improvement of communication and interaction skills, only one report [34] found generalisation of acquired skills into settings outside the group context. This could either be due to true insufficient generalisation of trained skills or a lack of outcome measures sensitivity. In general, the availability and choice of sensitive measures to detect training effects is crucial for intervention research $[19,26,30]$. Especially, instruments for assessing outcome in naturalistic settings with multiple informants and independent raters are pivotal. Furthermore, manualisation of curricula, control group-design and accurate sample characterisation are essential to facilitate comparability between treatment studies.

The objective of this study was to examine the effectiveness of an outpatient social skills group intervention for children and adolescents with autism spectrum disorder called "The Frankfurt Social Skills Training" (KONTAKT) [16, 17]. The programme aims at improving communication and social interaction skills and reducing the severity of autism-related psychopathology in different contexts. It is a manualised, long-term intervention, that enables tailored training sessions for a wide range of group constellations. In the current study, KONTAKT was evaluated over a period of almost one year, applying parent, teacher, expert and blind expert rating at pre-, post and follow-up assessments.

\section{Method}

\section{Frankfurt social skills training (KONTAKT)}

The KONTAKT for children and adolescents with autism spectrum disorder primarily focuses on learning to initiate social overtures, conversation skills, understanding social rules and relationships, identification and interpretation of verbal and nonverbal social signals, problem-solving, coping strategies and improvement of self-confidence. Participants are children and adolescents with sufficient cognitive and language abilities (IQ score above 70, functional language). They are assigned to a children's or adolescents' group of 4-7 participants each with an age range of 8-13 years and 13-19 years, respectively. The children's group meets weekly for $1 \mathrm{~h}$, the adolescents' groups meet bi-weekly for $1 \frac{1 / 2}{h}$. Child psychiatrists and clinical psychologists experienced in the treatment of autism spectrum disorders, carry out each of the sessions. Trainers and probands' parents meet regularly before school holidays (four times a year) to give mutual feedback about progress and problems regarding the participants' behaviours during the sessions, at home and at school, respectively. Principles of intervention are the combination of theoretical and practical elements, predictable rules, consideration of individual difficulties, sequential and progressive learning and recapitulation of previous training matters. KONTAKT follows a structured session schedule, which is composed of behaviour-based elements that are adaptively assembled. Sessions are mixed of obligatory, intermittent and flexible elements. Each session includes obligatory activities like a consistent opening format (warm-up) at the beginning and feedback at the end of a session. Herein, the participant gives an account of what he experienced the previous week and of his mood at the beginning of the session. In addition, before closing, feedback about today's session is provided by the participants. Intermittent elements are group-rules or homework. These elements are applied or repeated regularly. Rules, mainly concerning basic communication and interaction behaviour, like using eye-contact, listening to each other and cooperating are collected by the group itself and written on a poster, so that they can be recapitulated, if necessary. Homework comprises contact-exercises like calling a classmate on the telephone or a short report about an emotional situation in the subsequent week. Flexible elements are social interaction games, group activities, role play of everyday's social situations, group discussions and affect recognition. Topics for group discussions are social cognition, social relationships and private issues of the participants, including self- reflection and description of oneself and others. Affect recognition is trained by using pantomime games and standardised computer-based training programmes [4,9]. Details of intervention elements are described in Table 1.

\section{Participants}

Fifteen male and two female children and adolescents with autism spectrum disorder ranging in age from 9.3 to 20.3 years (mean $=14.7, \mathrm{SD}=3.4$ ) participated in this study. All participants were referred outpatients of the department of child and adolescent psychiatry at the University of Frankfurt. Inclusion criteria were: a clinical consensus diagnosis of an autism spectrum disorder (autism, Asperger's syndrome, atypical autism/PDD-NOS) derived 
Table 1 Intervention elements and procedure examples

\begin{tabular}{|c|c|c|}
\hline & Intervention principle & Examples \\
\hline \multicolumn{3}{|l|}{ Obligatory elements } \\
\hline \multirow[t]{2}{*}{ Opening format } & \multirow{2}{*}{$\begin{array}{l}\text { Warm-up activity, contact initiation, promotion } \\
\text { of interaction between group members }\end{array}$} & Say hello to each other \\
\hline & & $\begin{array}{l}\text { Give an account of what one experienced the previous } \\
\text { week and of one's mood at the beginning of the session } \\
\text { "I hand over to..." (name, eye-contact) }\end{array}$ \\
\hline Feedback & $\begin{array}{l}\text { Expression of personal opinions and feelings, } \\
\text { criticizing appropriately }\end{array}$ & $\begin{array}{l}\text { Give feedback (positive and negative) about today's session } \\
\text { Requests for the next session }\end{array}$ \\
\hline \multicolumn{3}{|l|}{ Intermittent elements } \\
\hline \multirow[t]{9}{*}{ Group rules } & \multirow{9}{*}{$\begin{array}{l}\text { Common and binding arrangement of basic } \\
\text { communication and interaction rules, } \\
\text { understanding of social conventions }\end{array}$} & Look at each other \\
\hline & & Listen to each other \\
\hline & & Do not interrupt others while they are speaking \\
\hline & & Confidentiality of information \\
\hline & & Address others directly \\
\hline & & Contribution to the session \\
\hline & & Do not laugh at anyone \\
\hline & & Do not insult others \\
\hline & & Speak friendly \\
\hline \multirow[t]{2}{*}{ Homework } & \multirow[t]{2}{*}{$\begin{array}{l}\text { "Generalization activity", complementary } \\
\text { practice of training matters in everyday's } \\
\text { situations }\end{array}$} & $\begin{array}{l}\text { Contact-exercise: calling a group member or a classmate } \\
\text { on the telephone, } \\
\text { Make an appointment with a classmate }\end{array}$ \\
\hline & & $\begin{array}{l}\text { Report about an emotional situation in the subsequent week: } \\
\text { "When did I feel sad and why?" }\end{array}$ \\
\hline \multicolumn{3}{|l|}{ Flexible elements } \\
\hline Social interaction games & $\begin{array}{l}\text { Basic interaction and communication games, } \\
\text { focussing cooperation, recognition of non- } \\
\text { verbal signals, eye-contact, watching each } \\
\text { other closely }\end{array}$ & $\begin{array}{l}\text { "What has changed?": participants sit together, one looks at the } \\
\text { others closely, then waits outside the room; one detail, i.e. two } \\
\text { participants change their glasses, is changed, the participant } \\
\text { comes back and has to detect what has changed }\end{array}$ \\
\hline \multirow[t]{4}{*}{ Group activities } & \multirow{4}{*}{$\begin{array}{l}\text { Foster a feeling of "group-belonging", cooperation } \\
\text { and partnership, practice of trained social skills }\end{array}$} & Go for a walk \\
\hline & & Shopping \\
\hline & & Bake cookies \\
\hline & & Museum visit \\
\hline \multirow[t]{7}{*}{ Role play } & \multirow{7}{*}{$\begin{array}{l}\text { Practical solutions and strategies for difficult social } \\
\text { everyday's situations: structured sequence with } \\
\text { definition of initial situation, role definition, } \\
\text { performance, feedback, repetition }\end{array}$} & Introducing oneself appropriately \\
\hline & & $\begin{array}{l}\text { Making contact } \\
\text { Making an appointment }\end{array}$ \\
\hline & & Making small-talk \\
\hline & & Coping with teasing \\
\hline & & Apologizing appropriately \\
\hline & & Standing up to someone appropriately \\
\hline & & Problem solving skills \\
\hline Group discussions & $\begin{array}{l}\text { Exchange of experiences, social cognition, social } \\
\text { relationships }\end{array}$ & $\begin{array}{l}\text { Conversation and interaction skills, social relations like friendship, } \\
\text { discussion of personal issues, self- and foreign-awareness }\end{array}$ \\
\hline & & Hands-on instructions: "how often may I call a classmate?" \\
\hline \multirow[t]{2}{*}{ Affect recognition } & \multirow[t]{2}{*}{ Recognition and interpretation of facial expressions } & Pantomime games \\
\hline & & $\begin{array}{l}\text { Standardized computer-based training programme (FEFA): } \\
\text { recognition of emotional expressions of human faces and } \\
\text { eyes with feedback explanation of the respective emotion and } \\
\text { illustrated examples }\end{array}$ \\
\hline
\end{tabular}

from ICD-10 research criteria and applying standardised diagnostic assessments using the German forms of the Autism Diagnostic Observation Schedule [27] and Autism Diagnostic Interview-Revised [10]. Exclusion criteria were: mental retardation (IQ $<70$ ), lack of functional language and severe comorbid organic health problems (e.g. Fragile $\mathrm{X}$ syndrome, tuberous sclerosis, intractable epilepsy). The consensus diagnosis was reached by a group of five experienced child psychiatrists and psychologists of the department, four of whom being involved in the KONTAKT evaluation. They were all clinically familiar with the children and adolescents and jointly evaluated and integrated the assessment results in diagnostic conferences to reach a maximum of expert agreement on the diagnoses. The consensus diagnosis had to be accepted by all five experts. According to this procedure, six probands fulfilled the criteria for (infantile) autism (F84.0), six for Asperger syndrome (F84.5) and five for atypical autism/PDD-NOS (F84.1; F84.9). General intellectual level was assessed by clinical psychologists using different psychometric tests. Tests were selected individually to yield best compliance and clinical validity [Raven progressive matrices (9), Wechsler intelligence scales for children-III or adults-revised 
(6); Kaufman's assessment battery for children (1) and culture fair test (1)]. In high functioning individuals with ASD such scales mostly lead to similar general IQ estimates [24]. The mean IQ in the sample was $93.4(S D=20.6)$. Language ability was estimated with the Peabody picture vocabulary test III (form a). The mean standard score across groups was $99.6(\mathrm{SD}=15.0)$. According to the Vineland adaptive behaviour scales information, adaptive behaviour level (ABC score) in the sample was 78.7 $(S D=19.6)$. For six participants, who had received a psychotropic medication prior to the KONTAKT pilot study for the treatment of excessive coexisting psychopathology, this medication was kept stable during the programme evaluation. Three participants were medicated with selective serotonin reuptake inhibitors for obsessive-compulsive symptoms, two with atypical neuroleptics for impulsive and aggressive behaviour and one with stimulants for hyperactivity. None of the participants received any other form of psychotherapy during the evaluation period. For programme administration, participants were assigned to three groups: an adolescent group $(n=4)$ without previous KONTAKT experience ("adolescent naïve"), a children's group $(n=6)$ without KONTAKT experience ("children naïve") and an adolescent group $(n=7)$, who had already received highly comparable KONTAKT training for two years prior to the evaluation ("adolescent experienced"). The main characteristics of these three groups are presented in Table 2.

\section{Instruments}

Three expert ratings, one blind expert rating, three parent and one teacher rating were obtained for the KONTAKT evaluation. Expert ratings comprised the diagnostic checklist for pervasive developmental disorders (DCL) [11], the checklist for group behaviour (CGB) [5], the global assessment of functioning scale (GAS) [13] and a blind video rating. The DCL is a ICD-10/DSM-IV based scale, which covers abnormalities in the areas of social interaction (DCL-S), communication (DCL-K) and stereotyped, repetitive behaviours and interests (DCL-ST). Each area contains four 4-point scaled (0-3) items. As it is a straight operationalisation of ICD-10/DSM-IV criteria for ASD the DCL can be considered a content valid scale. At T0, in the present sample, DCL scores and respective ADI-R (social, communication, stereotypies) and ADOS domain (social, communication) scores correlated between $r=0.25$ and 0.43 . The CGB is a rating scale comprising 19 six-point scaled items $(0-5)$ (Cronbach's alpha $=0.95)$ detecting social skills in group context (i. e., "is able to compromise with

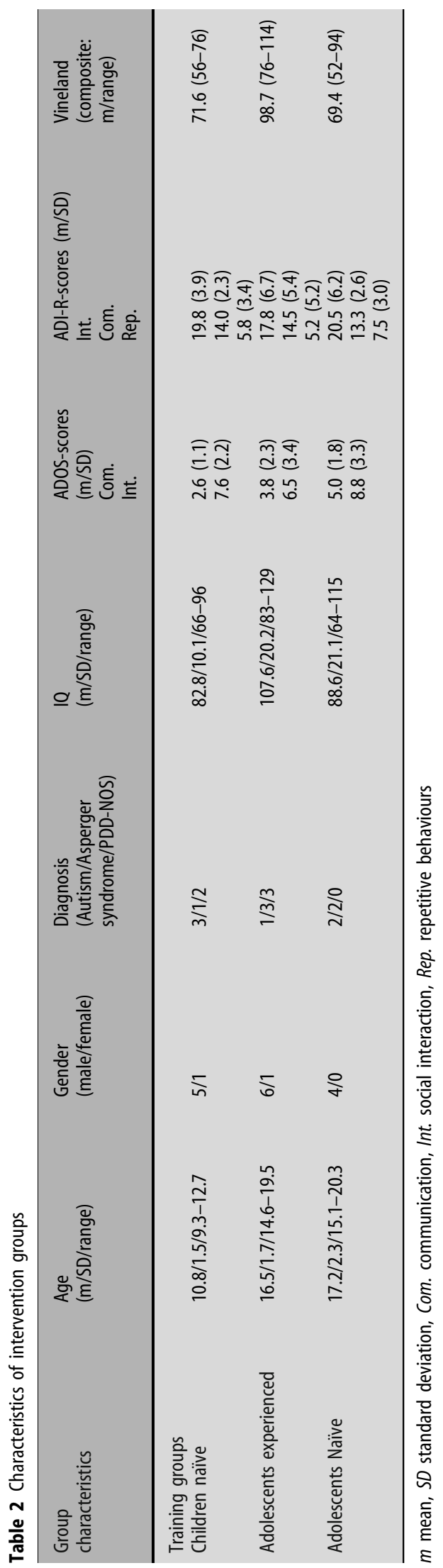


someone", "listens to others and is able to express him-/herself'). In the sample, CGB and ADI-R and ADOS domain scores for communication and social interaction correlated between $r=-0.23$ and -0.39 at T0. The GAS is a widely used rating scale to measure the level of everyday's psychosocial functioning scoring from 0 to 100 .

The blind expert ratings were collected as follows: pre training (T0) and at follow-up (T4) a standardised KONTAKT training component (obligatory "warmup" element) was videotaped in each of the three groups. In this component participants are to report how they currently feel, what they have experienced since the previous training session and if they have ideas or wishes for the upcoming session. Other participants are invited to raise questions or give statements, so that short interactions are likely. A coding system comprising four items on a Likert-like scale was generated in order to enable comparable assessments of the participants' behaviours during the warm-up. Two items refer to the formal accomplishment of the goal of this element, that is "Reports on one's actual feelings" (A1) and "Gives an account of a personal event" (A2). The other items aim to rate (B) "Socially communicative quality" (e. g. facial expression, eye-contact, use of gestures) and (C) "General clinical impression". Items A1, A2 and C are 7-point scaled (0-6), item B 8-point scaled (0-7). Item scores were summed to form a total score for behaviour in the standardised training compound. Four experienced clinical psychologists, not being involved in the department's autism research activities and the KONTAKT programme as well as unfamiliar to the participants rated the videotaped standardised training sequences. They were not informed about the study design and procedure of KONTAKT, but were aware of the expert rating being an outcome measure of a training evaluation, which is apparently an inevitable circumstance. Overall, there were six videotapes (T0 and T4 for each of the three groups). Those were rated independently by each of the four clinicians in randomised order. Interrater reliability (Spearman's Rho correlation) on item level was sufficiently high between raters with an average of $r=0.65$ for $\mathrm{A} 1$, $r=0.73$ for A2, $r=0.71$ for B and $r=0.70$ for C.

The parent ratings included a shortened and authorised version of the Parent Interview for Autism (PIA-CV-mini) [6], social competence scale (SKS) [7] and the family burden questionnaire (FaBel) [25]. The parent interview for autism-clinical version [33] was developed to measure change in rather low-functioning children with autism across a wide range of behavioural domains. Prior to the evaluation, the PIACV was modified for the current study in order to better fit the symptom patterns of older and highfunctioning children with autism spectrum disorder.
The resulting PIA-CV-mini comprises 31 five-point scaled items (0-4), which are assigned to six behavioural domains: social area (eight items, PIA-S), affective reactivity (five items, PIA-AR), interaction with peers (four items, PIA-INT), communication (six items, PIA-K), stereotyped behaviour (five items, PIAST) and need for sameness (three items, PIA-GL). The PIA-CV-mini items as whole showed an internal consistency of $r=0.79$. Its domain scores yielded correlations with the ADI-R and ADOS domain of $r=0.23-0.50$. The SKS is a parent questionnaire comprising 25 five-point scaled items (Cronbach's alpha $=0.89$ ) measuring general social skills (i.e. "is able to wait patiently, if necessary", "is able to express needs and wishes adequately"). In the sample, SKS and ADI-R and ADOS domain scores for communication and social interaction correlated between $r=-0.28$ and -0.48 at T0. The FaBel is a German adaptation of the internationally well established Impact-on-FamilyScale [31]. Its a 33 item questionnaire to assess the family burden caused by a mentally ill offspring. Items are scored on a 4-point scale. The items assess the general negative impact of parents, the description of social relationships, the concern for siblings, the financial impact and problems in coping as well as a total score. Aside from many studies on the original and other adaptation showing reliability and validity $[29,32]$, in a cross-sectional study of 273 families with children with chronic conditions and disabilities the FaBel demonstrated factorial and discriminant validity as well as good internal consistency $(r=0.89)$.

Teachers' opinions about participants' social skills were surveyed using the Questionnaire for the assessment of group behaviour (FEG) [8]. It's a 23 item questionnaire (Cronbach's alpha $=0.86$ ) measuring social behaviour in school setting. Items are scored on a 0 to 5 scale. Examples are "is able to collaborate with others", "initiates a conversation", "asks adults for help appropriately"). The FEG total score correlated $r=-0.26$ to -0.56 with the ADI-R and ADOS domain scores for social interaction and communication at $\mathrm{T} 0$.

The blind expert rating, CBG, SKS, FEG and GAS are social and adaptive competence scales with higher scores indicating a higher level of function, whereas the remaining measures are deficit scales, with higher scores indicating increasing impairment.

\section{Procedure}

The evaluation was conducted over a total period of 11 months (Nov 2005 to Sept 2006) at the Department of Child and Adolescent Psychiatry of Frankfurt/M. University. The naïve children group met weekly for one hour, both adolescent groups met bi- 
weekly for $1 \frac{1 / 2}{h}$ excluding holidays. This conceptual difference in training session density and duration was due to the children's shorter attention span, and their need for more frequent sessions in order to successfully enter the group context. Overall, the "experienced adolescent" group received 17 training sessions, the "naïve adolescent" 15 and the "naïve children's" group 29. A total of four experienced trainers (three child psychiatrists, one clinical psychologist) carried out the curriculum. Changing pairs of trainers led the sessions. In addition to the training sessions, trainers and probands' parents met regularly before school holidays (three times during evaluation period) to give mutual feedback about progress and problems regarding the participants' behaviour during the sessions, at home and at school, respectively. Particularly, these meetings were also used to instruct parents before holidays. Besides, parents are not actively involved in the KONTAKT training approach. Outcome assessments were undertaken at five points of time: pre-training (T0, Nov 2005), training I (T2, Dec 2005), training II (T3, Mar 2006), post-training (T4, Apr 2006) and follow-up (T5, Sept 2006). The CBG, SKS and FEG were collected at all occasions, the DCL, GAS, PIACV-mini and FaBel at T0, T3 and T4, the blind expert video ratings at $\mathrm{T} 0$ and $\mathrm{T} 4$ only.

\section{Data analysis}

The primary objective of this study was to evaluate the effectiveness of the KONTAKT programme. Therefore, first, within-subject effects over time were analysed. Participants' data from all three groups were pooled for this analysis. Sample size was rather small, but the principal assumptions of parametric testing were fulfilled (e.g. quantitative, normally or near-normally distributed dependent variables, homogeneity of variances of dependent variables). Thus, in order not to lose the metric and numerical values of the results and statistical power, analyses of covariance (ANCOVAs) for repeated measurement still seemed to best fit the design and data set. Group membership ("adolescent naïve", "adolescent experienced", "children naïve") and medication (any psychotropic medication, no medication) were entered as between-subject factor and age and IQ were covaried for. Due to minor violations of the sphericity assumption, Greenhouse-Geisser correction was applied. Alphas of $P<0.05$ were interpreted as significant and alphas of $P<0.10$ as trends. One-sided significance was chosen as improvements on the dependent measures were expected throughout (directed hypotheses). Partial eta squared $(\eta)$ are provided for a better comprehension of the net effects, with $\eta<0.06$ indicating small, $\eta=0.06$ to 0.14 medium and $\eta>0.14$ large effects.

In a second step, we sought to identify participant variables associated with programme effectiveness. For this purpose, difference scores expressing the gain in functioning or reduction in psychopathology, respectively, between $\mathrm{T} 0$ and $\mathrm{T} 4$ measurements for each proband were calculated, and viewed indicating intervention success. These scores were only generated for those scales that had yielded significant or trend within subjects effects over time in the prior ANCOVA (step one). Multiple linear regression models with these difference values as dependent variables and age, nonverbal IQ, language abilities as well as ADOS and ADI-R domain scores as predictors were calculated. Again, although overall sample size was small, main assumptions for parametric regression were not violated (independence of observations, linearity, reliability of measurement, homoscedasticity).

\section{Results}

Detailed findings and inference statistics for the assessments over time are shown in Table 3. Unfortunately, missing data had to be tolerated. Findings are based on complete data sets on the GAS from 15 probands, expert ratings from 14, DCL, CGB, SKS and PIA-CV-mini from 13, FaBel from 10 families. Full FEG data for all five assessments were only available for 5 participants. As the rate of missing data was partly high, and in order to control if results are biased by characteristics of participants interfering with response, statistical analyses were completed by also performing calculations using the method of last observation carried forward (LOCF) [22].

Descriptively, on average the participants of the KONTAKT programme improved on all outcome measures from T0 to T4. ANCOVAs using complete data sets only showed significant or trend effects on the GAS, SKS, all subscales of the DCL and two of six PIA-CV-mini subscales. Effect sizes were large for the FEG $(\eta=0.69)$, the GAS $(\eta=0.42)$, all subscales of the DCL $(\eta=0.30$ to 0.50$)$, the SKS $(\eta=0.25)$ and the PIA-CV-mini subscales interaction with peers $(\eta=0.33)$ and social behaviour $(\eta=0.18)$.

The "naïve children" group showed larger behavioural gains than the adolescent groups on the GAS $(F=3.7, P=0.03, \eta=0.38)$, the DCL-St $(F=2.9$, $P=0.04, \quad \eta=0.33)$ and the PIA-INT $(F=2.1$, $P=0.09, \quad \eta=0.28)$, and medicated participants exhibited a higher intervention effect than unmedicated on the DCL-K $(F=3.6, P=0.03, \eta=0.36)$ and the SKS $(F=2.5, P=0.07, \eta=0.31)$. There was no significant difference in program benefit between the naïve and the experienced adolescent groups. 
Table 3 Means and standard deviations at repeated measurement (T0-T4)

\begin{tabular}{|c|c|c|c|c|c|c|c|c|c|}
\hline & $\mathrm{N}$ & Maximum score & $\begin{array}{l}\mathrm{M}(\mathrm{SD}) \\
\mathrm{TO}\end{array}$ & $\begin{array}{l}\mathrm{M}(\mathrm{SD}) \\
\mathrm{T} 1\end{array}$ & $\begin{array}{l}\mathrm{M}(\mathrm{SD}) \\
\mathrm{T} 2\end{array}$ & $\begin{array}{l}M(S D) \\
T 3\end{array}$ & $\begin{array}{l}\mathrm{M}(\mathrm{SD}) \\
\mathrm{T} 4\end{array}$ & $F(P)$ & $\eta$ \\
\hline \multicolumn{10}{|c|}{ Expert ratings } \\
\hline CGB & 14 & 95 & $44.5(17.8)$ & $41.9(9.5)$ & $50.1(27.3)$ & $54.9(20.2)$ & $51.3(17.9)$ & $1.5(0.12)$ & 0.14 \\
\hline DCL-S & 14 & 12 & $7.2(1.6)$ & & & $5.1(2.0)$ & $6.3(1.3)$ & $11.9(0.00)$ & 0.50 \\
\hline DCL-K & 14 & 12 & $5.0(1.6)$ & & & $2.8(2.3)$ & $4.3(2.2)$ & $4.2(0.02)$ & 0.30 \\
\hline DCL-St & 14 & 12 & $2.9(1.7)$ & & & $1.0(1.2)$ & $1.5(1.1)$ & $10.9(0.00)$ & 0.48 \\
\hline GAS & 15 & 100 & $47.4(9.4)$ & & & $55.3(9.1)$ & $52.3(5.9)$ & $11.7(0.00)$ & 0.42 \\
\hline $\mathrm{BE}$ & 14 & 22 & $8.8(3.5)$ & & & & $9.7(3.4)$ & $1.5(0.24)$ & 0.05 \\
\hline \multicolumn{10}{|c|}{ Parent ratings } \\
\hline SKS & 13 & 100 & $46.1(14.6)$ & $45.3(18.1)$ & $50.4(12.5)$ & $50.8(12.9)$ & $53.3(16.9)$ & $2.0(0.08)$ & 0.25 \\
\hline PIA-S & 13 & 32 & $17.8(3.9)$ & & & $15.7(3.9)$ & $13.6(6.9)$ & $2.2(0.08)$ & 0.18 \\
\hline PIA-AR & 13 & 20 & $10.6(4.5)$ & & & $9.8(3.6)$ & $8.9(4.4)$ & $0.2(0.36)$ & 0.03 \\
\hline PIA-INT & 13 & 16 & $9.2(2.2)$ & & & $7.0(2.8)$ & $6.2(3.6)$ & $4.8(0.02)$ & 0.33 \\
\hline PIA-K & 13 & 24 & $11.2(3.9)$ & & & $9.3(3.5)$ & $9.5(3.4)$ & $1.5(0.13)$ & 0.13 \\
\hline PIA-St & 13 & 20 & $9.3(5.3)$ & & & $8.6(5.0)$ & $8.3(5.6)$ & $0.3(0.38)$ & 0.02 \\
\hline PIA-GL & 13 & 12 & $4.1(2.9)$ & & & $4.0(2.5)$ & $2.9(3.1)$ & $1.0(0.17)$ & 0.09 \\
\hline FABEL & 10 & 99 & 45.5 (13.9) & & & 47.3 (12.1) & 43.9 (13.3) & $0.4(0.34)$ & 0.04 \\
\hline \multicolumn{10}{|c|}{ Teacher ratings } \\
\hline FEG & 5 & 115 & $27.3(6.8)$ & $23.3(16.0)$ & $35.3(4.4)$ & 36.7 (7.6) & $38.5(6.6)$ & $2.2(0.16)$ & 0.69 \\
\hline
\end{tabular}

ANCOVA results are adjusted by age and IQ (medication and group entered as between-group factors), $P$ values are one-sided;

CGB checklist for group behaviour, $D C L$ diagnostic checklist for pervasive developmental disorders, GAS global assessment of functioning scale, $B E$ blind expert rating, SKS social competence scale, PIA parent interview for autism, FaBel impact-on-family-scale, FEG questionnaire for the assessment of group behaviour

Regression modelling to identify predictors of outcome at $\mathrm{T} 4$ revealed that both nonverbal IQ $(t=5.8, P=0.02)$ and language abilities $(t=5.6$, $P=0.03)$ had a significant positive influence on social skills improvement as reported by parents on the SKS. Age was found to have a positive effect on communication skills in the DCL-K $(t=3.0, P=0.02)$. That is, the older the participants the higher their communication problem reduction. Moreover, a positive relation between the severity of communication deficits on the ADOS prior to the programme and the intervention success on the DCL-S $(t=2.1$, $P=0.047)$ indicated that participants with a higher a priori level of communication problems benefited more from KONTAKT in terms of socialising.

Recalculating ANCOVA and regression applying LOCF slightly changed inference statistics $\left(F_{-}, t_{-}, P_{-}\right.$, $\eta$-values), but did not considerably change the direction of results. ${ }^{1}$

\section{Discussion}

KONTAKT $[16,17]$ is a manualised social skills curriculum for children and adolescents with autism spectrum disorder. Its effectiveness was examined in the current pilot study. Findings show that the programme might be useful for improving social skills

\footnotetext{
${ }^{1}$ Detailed data on the analyses using LOCF are available upon request for interested readers
}

and general adaptive functioning as well as reducing autistic symptoms with hints for a certain stability over time. However, despite noteworthy improvements following the KONTAKT training, there were also several non significant findings with small effect sizes, including the blind expert assessment, that limit interpretation in terms of effectiveness. The blind expert rating was assessed pre-training and at follow-up. The follow-up assessment was done within the first training session after a holiday period of 6 weeks. A possible reason for failure of significant improvement on this scale might be the fact that participants showed more difficulties in interacting and communicating within the first training session after the holiday period than within periods of regular training sessions. The trainers' clinical impression was that participants had to get used to each other anew. Therefore, the blind expert rating might have shown significant results if it had been applied in a subsequent training session. The most convincing improvement was found on autism symptom level. Interestingly, a positive effect of social skills training on autism-related psychopathology has also been recently reported by Tse et al. [34], using a parent-rating for general problem behaviour. Ratings by parents and teachers collected during the KONTAKT intervention in the present study also suggest some generalisation of behavioural gains to home and school situations. Even though based on a very small data set, the highest effect sizes were found for teachers' ratings on social competence skills, which is perhaps an important finding in terms 
of everyday's social adaptation of the probands. Within group situations during school lessons or during recreation time, teachers are, probably easier than parents, able to observe children interacting with peers and therefore practising fundamental social skills which KONTAKT tends to mediate. The comparably smaller effects for parent report on changes in social interaction following the training (e. g. PIAINT) are in line with this view.

There was a positive linear relation between IQ and verbal capacities on one hand and the extent of intervention success on the other hand, indicating that individuals already being "high-functioning" prior to the treatment benefited the most from KONTAKT in terms of social skills gain. Furthermore, we found that participants with a higher a priori level of communication problems on the ADOS benefited more from KONTAKT in terms of socialising in the expert rating. The latter indicates that KONTAKT accomplishes its objective, that is improving fundamental social skills like eye-contact, gestures and social responsiveness in real live settings. The more complex the social skills are, the more the improvement depends on a higher level of cognitive and verbal capacities. In addition, there are some hints that patients, who also received medication during the programme, improved more than unmedicated participants. This finding is contrary to the results of Tse et al. [34], who found no influence of medication on training effects. The children's group benefited more from the training than the adolescents' groups. This may be owing to the higher frequency of training sessions. Other explanations are higher ongoing natural maturation effects in the children or the fact, that the psychopathology is yet probably less chronic than in the teens and therefore more receptive to intervention. As KONTAKT is conceptualized as a long term intervention, an adolescent group being already familiar to the training was included in the study to examine possible differences in program benefit between naïve and experienced participants. Obviously, due to the lack of differences in benefits between experienced and naïve probands the acquisition of social skills seems comparable here. This perhaps underpins the usefulness and need for a long term alignment of social skills intervention.

The present study has several limitations, that may compromise the external validity of our findings. First, the design is a one group one treatment plan without a control group and alternative treatment. Thus, the net effect of KONTAKT or potential advantage over other forms of intervention cannot be estimated and there is a risk for an immanent bias. We implemented a blind expert rating pre- and post-training to compensate for the lack of control group. However, this yielded improvements only on a descriptive level, not sufficient to exclude observer-expectancy and Hawthorne effects. A multiple baseline case control design might have been more appropriate to determine effects. On balance, there was a quite consistent incline of positive treatment effects from baseline to post measurement on pivotal scales and a relative decline at follow-up measurement, which might be interpreted in terms of an expected behavioural trajectory in case of a true treatment effect. Second, mostly due to the conception of KONTAKT with a maximum of seven participants per group allowed, the total sample is quite small. Third, the extent of missing data, especially for teacher ratings, was partly substantial. Nevertheless, all three training groups showed amelioration, even at followup assessment. Forth, statistics were not adjusted for multiple comparisons, increasing the likelihood of significant findings by chance. Fifth, as different IQ measures were applied, a potential lack of comparability between intellectual estimates had to be tolerated. Thus, although the results of the current pilot study are promising, larger scale multicentre controlled research on the effectiveness of KONTAKT is needed to assure the results presented here. The inclusion of measures on participants' satisfaction with the group intervention and peer acceptance would also help to evaluate the treatment program. Clinically, group context and training procedure have been well accepted by the participants of the current study as well as by their parents. Participants seemed to enjoy the training and experienced a feeling of acceptance and assertion within the group. This is in line with findings of increased perception of peer social support among participants and increased selfconfidence in other studies $[2,34]$. Contentedness with applied intervention methods may be an important factor in motivating the participants to engage in social interaction outside the group context, which subsequently might enhance generalisation of skills to other settings. In order to further develop the usefulness of KONTAKT in terms of transfer of acquired skills, the inclusion of typically developing peers and children and adolescents with other psychiatric disorders, such as social phobia is desirable [14]. In a controlled and save setting, patients could mutually benefit from their respective strengths and learning strategies. 


\section{References}

1. American Psychiatric Association (1994) Diagnostic and statistical manual of mental disorders, 4th edn. Washington, DC, Author

2. Barry T, Klinger LG, Lee JM, Palardy N, Gilmore T, S. Bodin D (2003) Examining the effectiveness of an outpatient clinic-based social skills group for high-functioning children with autism. J Autism Dev Disord 33:685-701

3. Bauminger N (2007) Brief report: group social-multimodal intervention for HFASD. J Autism Dev Disord 37:16051615

4. Bölte S, Feineis-Matthews S, Poustka F (2003) Frankfurter Test und Training des Erkennens fazialen Affekts (FEFA). Frankfurt/M., J. W. GoetheUniversität. http://www.kgu.de/zpsy/ kinderpsychiatrie/Download/ index.htm

5. Bölte, S (2005a) Checkliste zur Beurteilung von Gruppenfertigkeiten (CBG). http://www.kgu.de/zpsy/ kinderpsychiatrie/Download/CBG.pdf

6. Bölte, S (2005b) Eltern-Kurzinterview zur Erfassung autistischen Verhaltens (PIA-CV-mini). http://www.kgu.de/ zpsy/kinderpsychiatrie/Download/ PIA_mini.pdf

7. Bölte S (2005c) Soziale Kompetenzskala (SKS). http://www.kgu.de/zpsy/ kinderpsychiatrie/Download/SKS.pdf

8. Bölte, S (2005d) Fragebogen zur Erfassung des Gruppenverhaltens (FEG). http://www.kgu.de/zpsy/ kinderpsychiatrie/Download/FEG.pdf

9. Bölte S, Hubl D, Feineis-Matthews S, Prvulovic D, Poustka F, Dierks T (2006) Facial affect recognition training in autism: can we animate the fusiform gyrus? Behav Neurosci 120:211-216

10. Bölte S, Rühl D, Schmötzer G, Poustka F (2006) Diagnostisches Interview für Autismus - Revidiert (ADI-R). Huber, Bern

11. Döpfner M, Lehmkuhl G (2000) Diagnosecheckliste (DCL) für Tiefgreifende Entwicklungsstörungen (TES). Diagnostik-System für psychische Störungen im Kindes- und Jugendalter nach ICD-10/DSM-IV (DISYPS-KJ). Hogrefe, Göttingen

12. Ehlers S, Gillberg C, Wing L (1999) A screening questionnaire for Asperger syndrome and other high-functioning autism spectrum disorders in school age children. J Autism Dev Disord 29:129-141

13. Endicott J, Spitzer RL, Fleiss JL, Cohen J (1976) The global assessment scale. A procedure for measuring overall severity of psychiatric disturbance. Arch Gen Psychiatry 33:766-771
14. Goldstein H (2002) Communication intervention for children with autism: a review of treatment efficacy. J Autism Dev Disord 32:373-396

15. Gresham FM, Elliott SN (1990) Social skills rating system. American Guidance Service, Circle Pines, MN

16. Herbrecht E, Poustka F (2007) Frankfurter Gruppentraining für Kinder und Jugendliche mit autistischen Störungen. Zeitschrift für Kinder- und Jugendpsychiatrie und Psychotherapie 35:33-40

17. Herbrecht E, Bölte S, Poustka F (2007) KONTAKT. Frankfurter Kommunikations- und soziales Interaktions-Gruppentraining für Autismus-SpektrumStörungen: Therapiemanual. Hogrefe, Göttingen

18. Krasny L, Williams B, Provencal S, Ozonoff S (2003) Social skills interventions for the autism spectrum: essential ingredients and a model curriculum. Child and Adolescent Psychiatric Clinics of North America 12:107122

19. Lord C, Wagner A, Rogers S, Szatmari P, Aman M, Charman T, Dawson G, Durand VM, Grossman L, Guthrie D, Harris S, Kasari C, Marcus L, Murphy S, Odom S, Pickles A, Scahill L, Shaw E, Siegel B, Sigman M, Stone W, Smith T, Yoder P (2005) Challenges in evaluating psychosocial interventions for Autistic Spectrum Disorders. J Autism Dev Disord 35:695-711

20. Marriage KJ, Gordon V, Brand L (1995) A social skills group for boys with asperger's syndrome. Aust NZ J Psychiatry 29:58-62

21. Mesibov GB (1984) Social skills training with verbal autistic adolescents and adults: a programme model. J Autism Dev Disord 14:395-404

22. Molenberghs G, Thijs H, Jansen I, Beunkens C, Kenward MG, Mallinkrodt C, Carroll RJ (2004) Analyzing incomplete longitudinal clinical trial data. Biostatistics 5:445-464

23. Ozonoff S, Miller JN (1995) Teaching theory of mind: A new approach to social skills training for individuals with autism. J Autism Dev Disord 25:415-433

24. Poustka, F, Dziobek I., Bölte, S (2008) The level and nature of autistic intelligence revisited. Poster presented at the 7th International Meeting for Autism Research in London
25. Ravens-Sieberer U, Morfeld M, Stein R, Reissmann C, Bullinger M, Thyen U (2001) Der Familien-BelastungsFragebogen (FaBel- Fragebogen) Testung und Validierung der deutschen Version der Impact on Family Scale bei Familien mit behinderten Kindern. Zeitschrift für Psychotherapie, Psychosomatik und Medizinische Psychologie 51:1-10

26. Rogers SJ (2000) Interventions that facilitate socialization in children with autism. J Autism Dev Disord 30:399409

27. Rühl D, Bölte $S$, Feineis-Matthews $S$, Poustka F (2004) Diagnostische Beobachtungsskala für Autistische Störungen (ADOS). Huber, Bern

28. Scahill L, Lord C (2004) Subject selection and characterization in clinical trials in children with autism. CNS Spectr 9:22-32

29. Sheeber LB, Johnson JH (1992) Applicability of the impact on family scale for assessing families with behaviourally difficult children. Psychol Rep 71:155-159

30. Smith T, Scahill L, Dawson G, Guthrie D, Lord C, Odom S, Rogers S, Wagner A (2007) Designing research studies on psychosocial interventions in autism. J Autism Dev Disord 37:354-366

31. Stein R, Riessman C (1980) The development of an impact-on-family-scale: preliminary findings. Med Care 4:465472

32. Stein R, Jessop DJ (2003) The impact on family scale revisited: further psychometric data. J Dev Behav Pediatr 24:9-16

33. Stone WL, Coonrod EE, Pozdol SL, Turner LM (2003) The parent interview for autism-clinical version (PIA-CV): a measure of behavioural change for young children with autism. Autism 7:930

34. Tse, J, Strulovitch, J, Tagalakis, V, Meng, L, Fombonne, E (2007) Social Skills Training for Adolescents with Asperger Syndrome and High-Functioning Autism. J Autism Dev Disord 37:1960-1968

35. Williams TI (1989) A social skills group for autistic children. J Autism Dev Disord 19:143-155

36. Williams White S, Keonig K, Scahill L (2006) Social skills development in children with autism spectrum disorders: a review of the intervention research. J Autism Dev Disord 37:1858-1868

37. World Health Organization (1992) The ICD-10 classification of mental and behavioural disorders. Clinical descriptions and guideline. WHO, Genf 